\title{
Visiones británicas del Mundo Atlántico español, c. 1740-1830 ${ }^{1}$
}

\author{
Gabriel PaquetTe \\ Assistant Professor of History \\ The Johns Hopkins University \\ Department of History \\ 3400 N. Charles Street \\ 301 Gilman Hall \\ Baltimore, MD 21218, Estados Unidos \\ gabriel.paquette@jhu.edu
}

Fecha de recepción: 01/06/2011

Fecha de aceptación: 15/12/2011

\begin{abstract}
RESUMEN
A medida que en las últimas décadas del siglo XVIII España llevaba a cabo sus reformas en la Península y en sus posesiones ultramarinas, sus estadistas emulaban a menudo las prácticas y las políticas tanto de sus rivales como de sus aliados. Dada la emergente supremacía marítima y colonial británica, no es de extrañar que los observadores españoles apuntaran a las políticas económicas y a las instituciones de su viejo rival con una mezcla de envidia, aversión y curiosidad ${ }^{2}$. Sin embargo, este interés estaba lejos de ser unilateral. Aunque las visiones británicas sobre España estaban todavía fuertemente influenciadas por la omnipresente Leyenda Negra, el conflicto armado permanente entre ambas potencias, la proximidad de sus posesiones coloniales, las ambiciones comerciales británicas sobre los mercados de la América española y las eficaces reformas coloniales hispanas desde 1760, hicieron que se escribiera, se debatiera y se discutiera sobre España en la vida pública británica con mayor frecuencia y apasionamiento desde 1750. En el periodo posterior a 1808, la participación británica en la guerra de la Independencia española y el interés general sobre las luchas que culminaron en la independencia de Hispanoamérica, llevaron a una reactivación y renovación de la fascinación británica sobre el mundo atlántico español, un interés que se mantuvo al menos hasta 1830. Esta contribución ofrece un breve estudio y análisis de las visiones y concepciones de los observadores británicos sobre España y su imperio entre fines del siglo XVIII y principios del XIX, y cómo éstas se abrieron paso en los debates británicos sobre la población, la eficacia del gobierno y el comercio. Se trata de demostrar que este interés británico sobre España era omnipresente y sorprendentemente influyente.
\end{abstract}

Palabras clave: España, reformas, Gran Bretaña.

\section{British Perceptions of the Spanish Atlantic World, c. 1740-1830}

\begin{abstract}
As Spain undertook the reform of its peninsular and overseas kingdoms in the latter decades of the eighteenth century, its statesmen often emulated the practices and policies of both their rivals and allies. Given Britain's emerging maritime and colonial supremacy, it is not surprising that Spanish observers pointed to their long-time rival's economic policies and institutions with a combination of envy,

\footnotetext{
1 Traducción de Óscar Recio Morales, revisada por el autor.

2 Estos temas se abordan en PAQuETTE, Gabriel: Enlightenment, Governance and Reform in Spain and its Empire, 1759-1808, Basingstoke y Nueva York, Palgrave Macmillan, 2008.
} 
loathing, and curiosity ${ }^{3}$ Yet the interest was far from one-sided. Though British perceptions of Spain were influenced strongly by the still ubiquitous Black Legend, the constant warfare between Spain and Britain, the proximity of their colonial possessions, British commercial ambitions in Spanish American markets, and Spain's efficacious colonial reforms in the period after 1760 meant that Spain was written about, debated, and discussed in British public life with great frequency and ferocity after 1750 . In the period after 1808, British involvement in the Peninsular War and the public interest in the struggles culminating in Spanish American independence led to a revival as well as a renewal of Britain's fascination with the Spanish Atlantic World, an interest which was maintained until at least 1830. This article offers a brief survey and analysis of British observers perceptions and conceptions of Spain and its empire in the late eighteenth and early nineteenth century and how those understandings and perceptions made their way into British debates about population, effective governance, and trade. It seeks to establish that British interest was ubiquitous and surprisingly influential.

Key words: Spain, reforms, Great Britain.

Los intercambios materiales, intelectuales y culturales entre España y Gran Bretaña han sido omnipresentes desde la época medieval ${ }^{4}$. Motivos políticos, dinásticos, religiosos y de otro tipo aseguraron que España y Gran Bretaña se observaran y emularan constantemente. El matrimonio de María Tudor con Felipe II y el envío de la Gran Armada por este monarca sólo fueron dos de los más espectaculares episodios de una serie de interacciones que a lo largo de los siglos determinaron las trayectorias posteriores de ambos países. La rivalidad estaba latente bajo la superficie y se manifiestó de múltiples maneras: por ejemplo, en la Conspiración de la Pólvora de 1605, en la que trece hombres conspiraron para hacer volar el Parlamento, relacionada de forma indeleble a Guy Fawkes, un católico que había luchado con el ejército español en Flandes. También en el teatro y en la literatura esta influencia mútua era prolífica. Como ha señalado Barbara Fuchs, "los escritores ingleses de la edad moderna miraban hacia España en busca de inspiración, y se basaron en gran medida en originales españoles" ${ }^{5}$. En términos más generales, los escritores políticos y económicos ingleses de fines del XVI y del siglo XVII utilizaron las imagenes de España cuando trataron de definir a la propia nación inglesa en contraposición a un "otro" a minusvalorar. El énfasis sobre la diferencia de España fue una de las muchas tácticas empleadas para consolidar la identidad inglesa. Esta "diferencia" podía adoptar múltiples formas, desde un énfasis sobre la excesiva religiosidad hasta una “orientalización” de España y su cultura ${ }^{6}$. En el siglo XVII, los apologistas de la colonización británica de los territorios reclamados por España desplegaron el argumento que afirmaba la

\footnotetext{
3 These themes are addressed in Paquette, Gabriel: Enlightenment, Governance and Reform in Spain and its Empire, 1759-1808, Basingstoke and New York, Palgrave Macmillan, 2008.

4 Ver, por ejemplo, las contribuciones incluidas en Bullón-FernÁNDEZ, María (ed.): England and Iberia in the Middle Ages, $12^{\text {th }}$-15 century: Cultural, Literary and Political Exchanges, Nueva York, Palgrave Macmillan, 2007.

${ }^{5}$ Fuchs, Barbara: «Beyond the Missing Cardenio: Anglo-Spanish Relations in Early Modern Drama», Journal of Medieval and Early Modern Studies, 39 (2009), p. 151.

${ }^{6}$ Sobre esta "diferencia" española en relación a Inglaterra y a la identidad inglesa, ver Fuchs, Barbara: «Sketches of Spain: Early Modern England's “Orientalizing” of Iberia», en Cruz, Anne (ed.): Material and Symbolic Circulation Between Spain and England 1554-1604, Aldershot y Burlington, Ashgate, 2008, p. 63; y Grifrin, Eric: «From Ethos to Ethnos: Hispanizing “The Spaniard” in the Old World and the New», CR: The New Centennial Review, 2 (2002), pp. 69-116.
} 
capacidad inglesa de mejora de la naturaleza en contraposición a su destrucción por los españoles, parte de un debate más amplio sobre la incapacidad del español para mejorar el medio ambiente ${ }^{7}$. John Elliott ha demostrado hasta qué punto los proyectos coloniales de España y Gran Bretaña en el Nuevo Mundo se debían uno a otro ${ }^{8}$.

La España imperial ofrecía a los comentaristas británicos algo más que una fantasía de mercados y minas lucrativos y sin explotar, y un gobierno despótico. La tan a menudo perniciosa - pero recurrente y ampliamente invocada- imagen de España fue una constante en el pensamiento político británico, especialmente con respecto a la población y al comercio colonial. La imagen de España como un imperio tiránico y comercialmente atrasado jugó un papel clave a medida que Gran Bretaña reexaminaba su propio imperio en las décadas finales del siglo XVIII. El periodo entre c. 1760 y 1790 fue especialmente importante porque hubo una conciencia creciente en Gran Bretaña, enfrentada a sus propias colonias incorregibles en Norteamérica, de que el imperio español -a través de una reforma integral- había recuperado sus fuerzas y logrado revertir su declive. Este creciente interés fue advertido por los contemporáneos. En 1779, por ejemplo, el anticuario inglés Richard Gaugh señaló que "The Kingdome of Spain is at present a favorite object of Recherche with our people and I trust both nations will benefit by it"'. La segunda mitad del siglo XVIII fue testigo de una auténtica explosión en el número de viajeros británicos dirigidos a España, aunque la mayoría de ellos no pertenecían a la variedad del Grand Tour, sino que más bien eran soldados, comerciantes y diplomáticos cuyas ocupaciones profesionales les llevaban a este país ${ }^{10}$. La mayor parte de estos escritores británicos "dieron una imagen de un imperio decadente y atrasado a los lectores británicos", repleta de fanatismo religioso y unas instituciones y prácticas políticas y económicas trasnochadas ${ }^{11}$. En cambio, para otros, especialmente para los irlandeses, España y su imperio americano se convirtieron en una tierra de oportunidades. No sólo los irlandeses católicos emigraron en un número significativo, sino que otros irlandeses (o de ascendencia irlandesa) encontraron sobradas oportunidades de ascenso al servicio del estado, tanto en la rama civil como militar, unas oportunidades que se habían cerrado para ellos en Gran Bretaña y su imperio ${ }^{12}$.

\footnotetext{
7 Ver Botella-Ordinas, Eva: «Debating Empires, Inventing Empires: British Territorial Claims Against the Spanish in America, 1670-1714», Journal of Early Modern Cultural Studies, 10 (2010), pp. 142-168.

8 Elliott, John H.: Empires of the Atlantic World: Britain and Spain in America, 1492-1830, New Haven y Londres, Yale University Press, 2006.

9 Cit. en Howarth, David: The Invention of Spain: Cultural Relations between Britain and Spain, 1770-1870, Manchester, Manchester University Press, 2007, p. xii.

10 La bibliografía sobre los viajeros británicos en la España del siglo XVIII es inmensa. Entre otros, ver RoBERTSON, Ian: Los Curiosos Impertinentes: Viajeros Ingleses por España, 1760-1855, Madrid, 1976; Guerrero, A.C.: Viajeros Británicos en la España del Siglo XVIII, Madrid, 1990; y MARTínez Ruiz, Enrique: «Viajeros extranjeros en la España del cambio de siglo: de Carlos IV a la Guerra de la Independencia», en GonzÁlez Cruz, David (ed.): Extranjeros y enemigos en Iberoamérica: la visión del otro. Del Imperio español a la Guerra de la Independencia, Madrid, Sílex, 2010 .

11 Hontanilla, Ana: «Image of Barbaric Spain in Eighteenth-century British Travel Writing», Studies in Eighteenth-century Culture, 37 (2008), pp. 121, 123, 134.

12 Para una magnífica visión general y análisis, ver Recio Morales, Óscar: Ireland and the Spanish Empire, 1600-1825, Dublín, Four Courts Press, 2010.
} 
La imagen de España desempeñó un papel crucial en varios debates británicos de finales del XVIII. Uno de los impactos más importantes de España sobre el pensamiento británico tuvo que ver con los debates sobre las causas del incremento de la población y su declive, siendo la asunción que a una población mayor y en crecimiento correspondía un mayor bienestar de su sociedad y era un condicionante previo para su prosperidad económica ${ }^{13}$. La expansión territorial desempeñó un papel crucial en los debates sobre la población británica. El temor a que la emigración a Norteamérica estuviera drenando a la población de la metrópoli y debilitando su fuerza estaba tan presente que el Parlamento contempló una prohibición de la emigración a fines de $1773^{14}$. Estos movimientos de población transatlánticos estimularon las comparaciones con España: los escritores británicos lucharon contra la idea de que la "decadencia" política (y declive demográfico) de la España del XVII había tenido su causa en su expansión imperial. David Hume atacó la afirmación de Montesquieu según la cual el imperio habría sustraído la fuerza de España. Llamando la atención sobre las ideas económicas del economista español Jerónimo de Uztáriz en una nota a pie de página -que Malthus aprovecharía posteriormente-, Hume rechazó la idea de que la expansión imperial hubiese despoblado a España, advirtiendo que "las provincias españolas que han enviado una mayor población a las Indias, están densamente pobladas; lo que proviene de su mayor riqueza". En cambio, sugirió Hume, la despoblación española formaba parte de un problema más complejo. Después de todo, remarcó Hume, aunque España pudiera haber "declinado con respecto a lo que era tres siglos atrás", tenía una población mayor que cuando era sólo una "agitada, anárquica e inestable" avanzadilla del Imperio romano ${ }^{15}$.

Escribiendo después de Hume, Robert Wallace discrepó, afirmando que la población de la Tierra era menor de la que había sido en siglos anteriores, atribuyendo la moderna "penuria" demográfica a una confluencia de restricciones físicas y causas morales. Para Wallace, la expansión territorial era menos importante que el modo de producción operativo en las colonias y culpó a los perniciosos efectos del oro y de la plata del presunto desfallecimiento de España. Wallace era un defensor de "la sencillez y el gusto entre los ciudadanos privados" y criticó la "dependencia" española del oro. Como Montesquieu, atribuyó la fluctuación de la población a la arbitrariedad y al despotismo político. Ridiculizó la expulsión de judíos y musulmanes como "un notable ejemplo de crueldad, locura y furia" y culpó al "despotismo" de ser contrario al aumento de la población. En España, sostenía Wallace, "la paz degenera comúnmente en la indolencia; el orden no es sino miedo al poder del tirano; como hay poca seguridad, la industria raramente prospera... ¿cómo puede esperarse una gran población en naciones privadas de industria y actividad?"16.

13 Una visión general sobre estos debates en GLAss, D.V.: Numbering the People: The Eighteenth-century Population Controversy and the Development of Census and Vital Statistics in Britain, Saxon, House and Farnborough, 1973.

14 Bailyn, Bernard: The Peopling of British North America: An Introduction, Nueva York, Knopf, 1986, p. 73.

15 Hume, David: «Of the Populousness of Ancient Nations», in Essays Moral, Political, and Literary, ed. Eugene Miller, Indianapolis, Liberty Fund, 1987, pp. 382, 419, 420, 448, 455.

${ }_{16}$ Wallace, Robert: A Dissertation on the Numbers of Mankind in Ancient and Modern Times: In Which the Superior Populousness of Antiquity is Maintained, Edimburgo, 1753, pp. 11-12, 17, 22, 60, 220, 250. 
Otros influyentes comentaristas siguieron, en mayor o menor medida, las explicaciones y argumentos de Hume y Wallace. Arthur Young, quizás el defensor más importante de la mejora de la agricultura de fines del siglo XVIII, representó a España como un albatros que presagiaba los peligros de un imperio no agrícola, dependiente de los recursos minerales. Como Wallace, Young creía que algunas formas específicas de actividad económica podían fomentar el crecimiento de la población. Young comparaba a Gran Bretaña con España: "esas montañas de metales preciosos sin duda tendían en gran medida a despoblar la vieja España" debido a que "el incentivo es tan brillante, la idea de una riqueza rápida e inmensa es tan encantadora que emigran los que bien podrían mantenerse en casa, intercambiando los pequeños beneficios de la industria por los imaginarios de la ociosidad". Los emigrantes británicos, al contrario, "no cambiaban la industria por la inactividad" debido al carácter intensivo de su trabajo agrícola ${ }^{17}$.

Hacia la década de 1780, sin embargo, el espectro de la superpoblación, en vez del de la despoblación, era unánime. Thomas Malthus, en su Ensayo sobre el principio de la población (1798), transformó los términos del debate sobre la población y convirtió en obsoleto la noción de que la expansión imperial era perjudicial al tamaño de la población. Malthus re-examinó la historia de la población española, reduciendo la importancia de factores como el sistema político y económico. Mientras repetía estereotipos poco halagadores sobre el imperialismo español ("ninguna colonia pudo haber sido peor gestionada que las de España en México, Perú y Quito"), su teoría sobre la población exoneraba a España de la responsabilidad de su escasa población. Desde su punto de vista, los determinantes ambientales eran mucho más influyentes ${ }^{18}$.

El programa de reformas borbónicas también estimuló la imaginación de los observadores británicos, empujando a los historiadores contemporáneos a revisar sus visiones sobre el desarrollo del imperio español. Las visiones tradicionales debían mucho a la profundamente arraigada Leyenda Negra ${ }^{19}$. Desde el siglo XVI, España había sido considerada sospechosamente por los observadores británicos como una aspirante a la monarquía universal, una bárbara destructora de los pueblos indígenas americanos y, en palabras del historiador Anthony Padgen, una "inflexible, intolerante, y en última instancia, corrupta tiranía" ${ }^{20}$. Las imagenes de una conducta ávida de España en el Nuevo Mundo se mantuvieron y fortalecieron por el sentimiento anti-español derivado del antagonismo religioso y de la siempre latente rivalidad imperial. La actitud británica era compleja, contrastando la decadencia española con sus todavía ingentes recursos. En un breve folleto de gran circulación escrito durante la guerra de la Oreja de Jenkins, John Campbell advirtió que el declive español era atribuible a los errores en su gobierno, lo que debería llevar a otras naciones a poner la atención

17 Young, Arthur: Political Essays concerning the Present State of the British Empire, Londres, 1772, pp. 434435.

18 Malthus, Thomas: An Essay on the Principle of Population, Londres, Penguin, 1970 [1798], p. 104. Otras referencias a España en pp. 86, 105, 107, 129, 133, 197.

19 Maltby, William S.: The Black Legend in England: The Development of Anti-Spanish Sentiment 1558-1660, Durham, Duke University Press, 1971.

20 Pagden, Anthony: Lords of All the World: Ideologies of Empire in Spain, Britain and France, c. 1500-1800, New Haven y Londres, Yale University Press, 1995, pp. 87, 116. 
para no caer en una condición semejante. Campbell señaló, no obstante, que España seguía siendo una opción viable, una "poderosa propietaria de grandes ventajas" que sólo "buscaba un ministerio capaz de usarlas y mejorarlas" 21 . En otras palabras, el músculo imperial español se había atrofiado, pero representaba todavía una amenaza creíble al pujante poder británico en el Nuevo Mundo. En el periodo previo, y en plena guerra de los Siete Años, el interés británico en la América española se incrementó notablemente, ya que muchos esperaban que el conflicto resultaría en un mayor -si no completamente libre- acceso a sus mercados. Sin embargo, la perspectiva de un dominio británico sobre esas provincias fue menospreciado, incluso después de que la toma británica de La Habana y de Manila en 1762 hicieran plausible la perspectiva de verdaderos avances en este sentido. Como un panfletista anónimo escribió, "la posesión de Sudamérica sería nuestra ruina", ya que Gran Bretaña no sería inmune a las condiciones que habían convertido a los españoles en "indolentes, míseros, débiles, al país de sus padres en un desierto y sus colonias a la manera de un sepulcro" 22 .

Por supuesto, una actitud más tolerante era siempre contingente a unas relaciones pacíficas anglo-españolas. De hecho, la alianza de España con Francia en apoyo de las colonias británicas rebeldes de Norteamérica en 1779, llevó a Edmund Burke a reprochar a los hispanófilos en la Cámara de los Comunes: “ $¡ O h$, cómo nos han engañado! ¡Cómo hemos dormido noche tras noche, soñando con la buena fe de España!"23. A lo largo de las últimas décadas del siglo XVIII, además, la política económica y colonial española continuó siendo objeto de duras críticas por parte de los escritores británicos, desde los viajeros y diplomáticos hasta los economistas políticos. La principal queja era que España no había sabido explotar la prodigiosa riqueza natural de sus posesiones ultramarinas. En la década de 1780 Joseph Townsend señaló que "ningún país se ha inventado un sistema más ruinoso para las finanzas, o uno menos amigo de la industria y del comercio". De hecho, la reforma emprendida fue considerada como defectuosa o pasada de moda y "los mejores escritores políticos españoles se parecen a los perros de caza retrasados que siguen el rastro viejo, mientras que los más rápidos ya están en posesión de la pieza" ${ }^{24}$.

Sin embargo, aunque tales representaciones negativas proliferaron, fue la desaprobación de Adam Smith sobre el sistema colonial español lo que demostró ser a la larga lo más influyente. En particular, Smith repudió el monopolio colonial como un "peso muerto", algo que retardaba la prosperidad de las colonias debido al aumento del precio de sus productos en el exterior. De esta manera, el monopolio colonial "obstaculiza y grava a la industria de todos los países". Además, "hace menos segura" la prosperidad de la metrópoli a largo plazo, ya que "su comercio, en lugar de transitar a lo largo de un gran número de pequeños canales, se le ha enseñado a navegar sobre todo en un único gran canal". Los costes de la defensa militar, sostenía Smith, eran exorbitantes, derrochando el dinero de los contribuyentes y de los consumidores. Smith utilizó a España como un test de prueba sobre los defectos

\footnotetext{
Campbell, John: A Concise History of Spanish America, Londres, Dawson's, 1972 [1741], p. 79.

2 ANÓNImo: Reflections on the terms of Peace, Londres, 1763, pp. 35-36.

23 Parliamentary History of England, Londres, 1814, vol. XX (1779), p. 896.

24 Townsend, Joseph: A Journey through Spain in the Years 1786 and 1787, Londres, 1792, vol. II, pp. $226,394$.
} 
del monopolio, que "casi han desequilibrado los buenos efectos naturales del comercio colonial" 25 . Su observación sintetizaba la noción generalizada de que el imperio español había sido adquirido y conservado impropiamente, algo ciertamente contrario a la auto percepción británica - siguiendo la descripción de David Armitage-, de un "imperio [británico] oceánico basado en el comercio y la población, no un imperio de conquista" ${ }^{26}$. Todo este desprecio intelectual y concreta beligerancia, no había reducido, sin embargo, la importancia del comercio hispano-británico. En la década de 1780, Gran Bretaña seguía siendo el principal cliente de España, mientras España era el quinto mayor socio comercial de Gran Bretaña en el continente ${ }^{27}$.

Aunque las décadas posteriores al acuerdo de paz de 1763 estuvieron marcadas por fuertes disputas sobre las Malvinas (Falkland Islands) y la Costa de los Mosquitos, los líderes políticos y los intelectuales británicos modificaron su postura hostil precedente hacia España, al menos hasta 1779. Esta visión positiva se debió a la reactivación económica y administrativa en España, a menudo asociada al reinado de Carlos III. El mejor ejemplo del ablandamiento de las actitudes hacia el país ibérico estuvo representado por William Robertson, cronista real de Escocia y rector de la Universidad de Edimburgo, cuya History of America apareció en 1777 y reinterpretó la historia del imperio español a la luz de las reformas llevadas a cabo por el gobierno de Carlos III. En su introducción, Robertson lamentó la "cortedad política" y la "anti-liberal" ocultación española de sus "operaciones en América", pero señaló que un importante cambio estaba en marcha ${ }^{28}$. Esbozó una rígida frontera entre las buenas intenciones de la España metropolitana y la "voracidad destructiva de los aventureros particulares". Empleando esta imagen de ineficacia de la corona, Robertson puso en discusión las bases de la Leyenda Negra. La distancia también sirvió como pretexto para exculpar a España de su responsabilidad en la falta de aumento de la población, la promoción del comercio y el fomento de la agricultura en América. En el volúmen octavo de su History, Robertson trazó el progreso económico de las colonias españolas del Nuevo Mundo. A pesar de que frecuentemente citó, y tomó liberamente argumentos de Adam Smith, Robertson defendió las primeras políticas españolas de monopolio y de metales preciosos como algo "natural, y tal vez necesario" en un contexto histórico específico. Los pioneros esfuerzos de España como potencia colonial rendían excusable sus primeros fallos. Robertson mostró indulgencia por el deseo de "riqueza inmediata" y elogió el monopolio comercial que colocó a las colonias americanas en una posición de "tutelaje perpetuo" y mantuvo la "supremacía de la madre patria" durante 250 años. Robertson explicó los problemas económicos del imperio español atribuyendo su lento crecimiento a las "enfermedades de los climas malsanos" y a la carga de "conducir a un territorio, cubierto de bosques, a la civilización”. Cierto que Robertson criticó la persistencia de ciertos rasgos del colo-

\footnotetext{
25 Sмiтh, Adam: An Inquiry into the Nature and Causes of the Wealth of Nations, Oxford, Oxford University Press, 1976, vol. II, pp. 592-604 passim.; vol. I, pp. 609-610.

26 Armitage, David: The Ideological Origins of the British Empire, Cambridge, Cambridge University Press, 2000 , pp. 3,8 .

27 Ehrman, John: The British Government and Commercial Negotiations with Europe 1783-1793, Cambridge, Cambridge University Press, 1962, p. 18.

28 Robertson, William: The History of America, $6^{\text {th }}$ ed., Londres, 1792, vol. I, pp. v, x.
} 
nialismo español porque éstos disminuyeron el "equilibrado y perseverante espíritu de la industria". Pero elogió a España por haber resistido a la tentación de crear una compañía de comercio exclusiva, como la contemporánea East India Company británica. Robertson concluyó su relato con una reivindicación de las reformas borbónicas, que según él fueron inspiradas por "sentimientos más liberales y de más amplias miras". Alabó a Carlos III por haber repudiado los "estrechos prejuicios", adoptando un comercio libre limitado, y supervisando un "arduo esfuerzo para revivir el espíritu de la industria donde éste había declinado". Sin embargo, argumentó que la economía peninsular española requería de una drástica reforma antes de que "la industria y las manufacturas pudieran recuperar su extensa actividad" 29 . Ninguna sorpresa, Robertson fue atacado por los críticos por "trabajar para paliar los enormes crímenes" y de "jocultar los hechos atroces de España bajo una burbuja de palabras sin sentido!".

La invasión napoleónica y la ocupación de la península Ibérica ocasionó por supuesto una completa reevaluación de las relaciones británicas con España. El apoyo británico a los patriotas portugueses y españoles y su intervención militar, decisiva en la expulsión de las tropas francesas del territorio español, hizo que muchos jóvenes entrasen en contacto con la cultura y el paisaje español. Se estima que al menos 40.000 soldados británicos murieron en territorio español a finales de la guerra de la Independencia. El apoyo a los patriotas españoles adoptó muchas formas más allá del auxilio militar, desde el sustento moral y material suministrado por Lord y Lady Holland, hasta los provocativos artículos de Lord Brougham publicados en la Edimburgh Review. Incluso un reaccionario empedernido como Coleridge afirmó que "no fue hasta la insurrección española que los ingleses de toda condición recurrieron, en su totalidad, a los viejos principios ingleses, y hablaron con el viejo entusiasmo de sus Hampdens, Sidneys y Miltons" ${ }^{30}$. Los debates en las Cortes de Cádiz, que culminaron en la Constitución de 1812, también despertaron un gran interés sobre España en Gran Bretaña. La experiencia española, civil o militar, estaba detrás del incremento de las publicaciones en las primeras décadas del siglo XIX, que incluían los influyentes relatos escritos por Robert Southey y Sir Charles Napier.

La restauración de Fernando VII en 1814 condujo a un nuevo tipo de interacción con España: los exiliados liberales se agolparon en Londres, especialmente entre 1814-1820 y 1823-1833, donde su situación y sus aspiraciones políticas fueron objeto de simpatía (aunque ellos mismos no se salvaron de los peligros de la miseria). La solidaridad mostrada por los sectores radicales de la opinión pública británica con la comunidad española en Londres, capturada de forma conmovedora en Life of John Sterling (1851) de Thomas Carlyle, se extendió a la acción política y militar. En 1835, se reclutaron 12.000 efectivos destinados a la Legión Británica para luchar en las guerras carlistas al lado de los Cristinos, un esfuerzo descrito por Howarth como "el último, el más desorganizado y el más excéntrico apoyo gubernamental a una intervención militar en España"31. A estos extenuantes esfuerzos militares se

\footnotetext{
29 Ibidem, vol. I, pp. 158, 210, 229, 253, 277; vol. III, pp. 98-100, 256, 270-275, 288, 303, 314, 320, 337.

30 Cit. en HowarTH: op. cit. (nota 9), p. 31.

31 Ibidem, p. 57. Ver también BRETT, Edward M.: The British Auxiliary Legion in the First Carlist War in Spain 1835-1838: A Forgotten Army, Dublín, Four Courts Press, 2005.
} 
unió un renovado interés cultural por España, especialmente en las bellas artes. Los pintores británicos viajaron a España en gran número y uno de ellos, David Wilkie, denominó a España en una cita famosa de 1828 como "la salvaje y furtiva reserva de caza de Europa". Algunos pintores, como David Roberts, hicieron una pequeña fortuna con sus litografías de Andalucía a principios de la década de 1830 y un torrente de libros alimentó el gusto del público británico por el "exotismo" de los paisajes españoles y las formas culturales que proliferaron en los años 1830 y 1840 . A este amplio interés del público general, habría que añadir por supuesto el gusto de la clase alta británica por el arte español, especialmente la pintura, lo que llevó a una adquisición acelerada de pintura española en las décadas de 1830 y 1840 . George Villiers, posteriormente cuarto conde de Clarendon y embajador británico en España en la segunda mitad de la década de 1830, fue una de las fuerzas impulsoras detrás de este interés ${ }^{32}$.

No puede decirse, sin embargo, que las actitudes hacia España fueran abrumadoramente positivas a comienzos del siglo XIX. La alianza española con la Francia revolucionaria después de 1796 hizo que Gran Bretaña y España se enfrentaran de nuevo hasta que los acontecimientos de 1808 cambiaron las cosas por completo. La armada real británica cortó en gran medida a España de sus colonias americanas desde 1797 y, por supuesto, buena parte de la flota española fue derrotada en Trafalgar, lo que agravó una situación ya de por sí desastrosa. Las tácticas de mano dura llevadas a cabo por Fernando VII tras su restauración no ayudaron a congraciarse con este monarca, mientras que la orientación de su política exterior hacia los caprichos de París, y no hacia los de Londres, produjeron claramente un efecto negativo en las relaciones anglo-españolas. Pero las actitudes británicas fueron moldeadas de forma decidida, sobre todo, por la llamada de los mercados y minas sudamericanos. Los movimientos de independencia de la América española también condujeron en Gran Bretaña a una reformulación de la Leyenda Negra, ahora invocada para justificar la agitación que intentó romper el Viejo Mundo del Nuevo. El comercio de contrabando con la América española aumentó considerablemente después de 1796 y algunos observadores británicos creyeron que la América española podría pasar de manos españolas a las británicas. Tal emoción alcanzó su apogeo con la toma temporal de Buenos Aires por Home Popham en 1806, aunque disminuyó al poco tiempo. Con todo, la participación de América Latina en el total del comercio exterior británico creció significativamente en las décadas siguientes. Surgió la convicción común de que la industria británica y el ingenio tecnológico podría generar riqueza de los amplios recursos que los primitivos métodos españoles y su indolencia habían dilapidado.

Sin embargo, no todas las imágenes británicas sobre la América española estuvieron animadas por las visiones de la explotación económica. Muchos liberales británicos estaban entusiasmados con las perspectivas políticas del continente. Jeremy Bentham, por ejemplo, consideró a la América española como un laboratorio para sus ideas. Tras conversar con el cosmopolita revolucionario de origen venezolano Francisco de Miranda, a quien conoció a través de James Mill, Bentham aspiró momentá-

32 Muchos de estos aspectos son discutidos en amplitud por HowARTH: op. cit. (nota 9); Wilkie citado en HowARTH. 
neamente a emigrar con el fin de redactar las constituciones de las nuevas entidades políticas que nacían a partir de 1808. Continuó su correspondencia con los líderes revolucionarios hasta bien entrada la década de 1820, incluyendo a Bolívar, bombardeando a estos líderes con su asesoramiento legislativo ${ }^{33}$. Los grandes movimientos culturales y las tendencias, especialmente la dimensión política del Romanticismo, llevó a algunos observadores británicos a justificar la disolución del imperio español. Representando una Europa anquilosada y decadente, miraban más allá del Viejo Continente para la regeneración y la reconexión con sus antiguos ideales ${ }^{34}$. Desde las islas Británicas, miles de jóvenes acudieron a Sudamérica para luchar en los ejércitos revolucionarios, y muchos siguieron en este continente después de la independencia $^{35}$. La América española resultó ser un lienzo perfecto para las fantasías británicas.

Esta imagenes, por supuesto, fueron suavizadas con la simpatía hacia los patriotas españoles que luchaban contra la ocupación extranjera y dieron lugar a respuestas aparentemente contradictorias. El lamento de Lord Byron por una España víctima del "buitre de la Galia con sus alas desplegadas", se complementó con la caracterización de la impotencia de un "pueblo sin rey en un estado débil" ${ }^{36}$. Con todo, por lo menos en los círculos oficiales, hubo renuencia a reconocer la independencia de las nacientes entidades políticas hispanoamericanas, ya que algo así podía efectivamente repudiar la soberanía española. George Canning argumentó que sería "cruel, injusto, desleal y poco generoso" interferir con el derecho de España a una "recuperación de sus posesiones coloniales, si estuviera en una posición de poder recuperarlas". En última instancia, el interés pecuniario de la City de Londres y el equilibrio geopolítico de Europa llevó al gobierno de Canning a romper con su política anterior y a reconocer la independencia de la América Latina.

Si bien el impacto de la imagen y el ejemplo de España en la Gran Bretaña de los siglos XVI y XVII han sido ampliamente reconocidos, tanto la continuidad como la transformación de esa imagen a fines del siglo XVIII y principios del XIX raramente han sido apreciadas. Como esta contribución ha pretendido demostrar, España siguió siendo una piedra angular en los debates británicos y un objeto de investigación para los viajeros británicos, estadistas y observadores culturales. Lejos de una imagen monolítica o estática, los comentaristas británicos fueron sensibles a la evolución de los acontecimientos en España, aunque sus análisis estuvieron a menudo contaminados por los elementos de la Leyenda Negra. A medida que tanto el imperio británico como el español entraban en períodos de transición y transformación, crecía el nivel de intercambio y se incrementaba la emulación y su interés mútuo.

\footnotetext{
33 Williford, William: Jeremy Bentham on Spanish America: An Account of his Letters and Proposals to the New World, Baton Rouge y Londres, Louisiana State University Press, 1980.

34 Cole Heinowitz, Rebecca: Spanish America and British Romanticism, 1777-1826. Rewriting Conquest, Edimburgo, Edinburgh University Press, 2010.

35 Brown, Matthew: Adventuring through Spanish Colonies: Simón Bolivar, Foreign Mercenaries, and the Birth of New Nations, Liverpool, Liverpool University Press, 2006.

${ }^{36}$ Lord Byron: Childe Harold's Pilgrimage, canto 1, stanzas 35, 86.
} 